\title{
GPS and GSM Based Self Defense System for Women Safety
}

\section{Sriranjini $\mathbf{R}^{1,2 *}$}

${ }^{1}$ Electrical and Electronics Engineering, PA College of Engineering and Technology, Tamil Nadu, India

${ }^{2}$ Department of Electrical Engineering and Information Technology, RWTH Aachen University, Germany

\begin{abstract}
The world is becoming unsafe for women in all aspects. The crimes against women are increasing at a higher rate. The employed women are feeling unsafe due to increasing crimes. This paper proposes a quick responding mechanism that helps women during trouble. When someone is going to harass, she can press the button that is attached to the device and the location information is sent as an SMS alert to few pre defined emergency numbers in terms of latitude and longitude. The microcontroller used is PIC16877A. It is interfaced with a push button, a GPS module, a GSM modem and a speech circuit (ISD1820PY). If the switch is pressed, it activates the speech circuit to capture the attention of the people nearby for help. The program is developed in embedded language to demonstrate the system capability in providing real time response. Thus the girl can be safe and she can feel protected.
\end{abstract}

Keywords: PIC16F877A; GPS; GSM; ISD 1820PY

\section{Introduction}

Even in this modern era women are feeling insecure to step out of their house because of increasing crimes in our country like harassment, abuse, violence etc., The corporate and IT sector are currently in boom. Many women are working in corporate even in night shifts. There is a feeling of insecurity among the working women.

The proposed device is more like a safety system in case of emergency. This device can be fitted in a jacket (similar to a blazer for women). It is an easy to carry device with more features and functions. The emergency push button is held to one of the buttons of the jacket. The main purpose of this device is to intimate the parents and police about the current location of the women. A GPS system is used to trace the current position of the victim and a GSM modem is used to send the message to the pre defined numbers. There are several applications that reduce the risk of sexual abuse by sending SMS but in our model we also provide an audio circuit which is more useful for physically challenged people.

The block diagram of the proposed system is shown in Figure 1. The microcontroller acts as an embedded computing system and it controls the activities of all the subsystems. The microcontroller is

\section{BLOCK DIAGRAM}

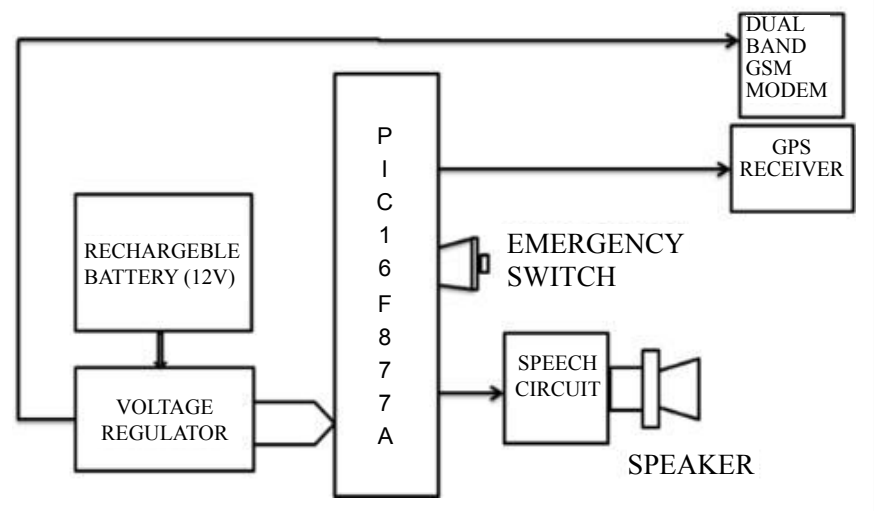

Figure 1: The block diagram of the proposed model. interfaced with all the other modules of the device. The program for PIC microcontroller is done in Embedded C language and is dumped using a kit.

\section{Existing System}

GSM and GPS based vehicle tracking system is currently used. This system consists of GPS module attached to a button in the vehicle. In case of emergency, the switch attached to the GPS can be pressed. The GPS that is used here is Teltonika FM1100 [1-3]. When any problem occurs the employee travelling in the vehicle presses the switch attached to the GPS. GSM module attached to this GPS and switch is used to send the message to a special team of the organization. Although this system seems to be efficient, at times there are some drawbacks because the drivers may not be trustworthy.

Another existing method is an application based prototype [2]. It is interfaced with GPS, GSM and a spy camera. The user must register the emergency numbers. This is an android app which provides all facilities but it has a disadvantage that if the mobile phone of the victim is thrown away by the opposing person, this model cannot be used efficiently. To overcome these disadvantages we propose a model.

\section{Proposed Model}

The device consist of

- $\operatorname{GSM}($ SIM 900A)

- GPS(G702-001UB)

- Micro controller ( PIC 16F877A)

- Speed circuit (ISD1820PY)

- Voltage regulator circuit

- Speaker

*Corresponding author: Sriranjini R, Department of Electrical Engineering and Information Technology, RWTH Aachen University, Germany, Tel: +49241801; E-mail: sriranjinie@gmail.com

Received May 23, 2017; Accepted July 10, 2017; Published July 26, 2017

Citation: Sriranjini R (2017) GPS and GSM Based Self Defense System for Women Safety. J Electr Electron Syst 6: 233. doi: 10.4172/2332-0796.1000233

Copyright: @ 2017 Sriranjini R. This is an open-access article distributed under the terms of the Creative Commons Attribution License, which permits unrestricted use, distribution, and reproduction in any medium, provided the original author and source are credited. 
The microcontroller (PIC16F877A) acts as an embedded computing system and controls the activities of all the subsystems. It is interfaced with Emergency Switch, GPS Receiver, GSM MODEM, and Speech Circuit. In case of emergency the trigger button is pressed [1].

The system tracks the location information from the GPS and prepares a text SMS containing the present location information and send SMS through GSM modem to the police control room and distress message to the pre programmed mobile number. Using the information supplied by this system, the location using GPS and can be traced through Google maps [4-6]. Thus the girl will be safe and she feels protected. The block diagram of the proposed model is shown in Figure 1.

\section{PIC16F877A}

The IC consists of 40 pins. It is an 8 bit microcontroller. It has 5 $\mathrm{I} / \mathrm{O}$ ports, 15 interrupts. The $5 \mathrm{I} / \mathrm{O}$ ports are named as port $\mathrm{A}$, port $\mathrm{B}$, port $\mathrm{C}$, port $\mathrm{D}$ and port $\mathrm{E}$. Among these 5 ports port $\mathrm{A}$ and port $\mathrm{E}$ are analog by default. It consists of various registers out of which TMR2, RCSTA and INTCON register are used mostly. All the modules used are interfaced with the microcontroller. The microcontroller is operated in crystal mode with a frequency of $4 \mathrm{MHz}$.

\section{Features of PIC16F877A}

- Program Memory Type

Flash

- Program Memory (KB)

14

- CPU Speed (MIPS)

- RAM Bytes 5

- Data EEPROM (bytes)

- Digital Communication Peripherals 1-SPI, 1- I2C1-MSSP (SPI/I2C)

- Capture/Compare/PWM Peripherals

- Timers

x 16-bit

- $\mathrm{ADC}$

- Comparators

- Temperature Range(C)

- Operating Voltage Range (V)

- Pin Count

1-UART,

\section{CCP}

2 x 8-bit, 1

$8 \mathrm{ch}, 10-\mathrm{bit}$

2

-40 to 125

2 to 5.5

40

\section{GSM}

Global System for Mobile Communication (GSM) SIM card is a device to send the location obtained through GPS. The GSM SIM card number is registered with the system. In this proposed device the GSM acts as a receiver while the GPS acts as a transmitter. The received values from the transmitter are sent as an SMS to the few predefined emergency numbers. The receiver pin of GSM is interfaced with $16^{\text {th }}$ pin of the microcontroller. The supply voltage is about $3.4 \mathrm{~V}$ which is supplied from the voltage regulator circuit.

\section{Features of SIM 900A}

- Low cost.

- $\quad$ RS 232/interface DB port.

- Voice communication port.
- On board voltage regulator.

- Power /single led indication.

- SMA connector for antenna connection.

- This module can be easily interfaced with it AT commands over TTL interface.

\section{GPS}

It consists of six wires out of which three wires are used for connection. The blue wire is the transmitter wire which is connected to the $15^{\text {th }}$ pin of the microcontroller. Voltage supply is about $3.3 \mathrm{~V}$ to $5 \mathrm{~V}$.When trigger button is pressed, GPS starts receiving signals from 8 satellites out of the 24 satellites in the orbit [3]. Once if the connection is established the latitude and longitude values of the current location are obtained. The GPS acts as a transmitter. The $5 \mathrm{~V}$ supply is given to the GPS from the microcontroller (Figure 2).

\section{Features of G702-001UB}

- $\quad$ Received bandwidth is about $1575.42 \mathrm{MHz}$.

- 50 tracking channels are available.

- Accuracy in terms of time is about 1 us.

- The maximum altitude is about $18000 \mathrm{~m}$.

- Maximum speed is about $500 \mathrm{~m} / \mathrm{s}$.

- Sensitivity of tracking is about $162 \mathrm{dBm}$.

- Operating temperature is about 30 degree to 80degree.

\section{Speech circuit (ISD1820PY)}

The component used for speech circuit is ISD1820PY. The required sentence or a phrase can be recorded [2]. There are three buttons namely REC, PLAYE, PLAYL. The REC button is used as an input button because it is used to record the required sentence or a phrase. The required input sentence is recorded with the help of MIC when the REC button is enabled. If the PLAYE button is pressed then the recorded sentence is continuously played. When the PLAYL is pressed the sentence is heard only up to the time of pressing the button because it does not identify the end of the sentence. The voltage supply is given from the microcontroller. Further two connections are given to the speaker through which sound is heard (Figure 3).

\section{Features of ISD1820PY}

- $\quad$ Playback can be edge or level activated.

- Automatic power down mode is available.

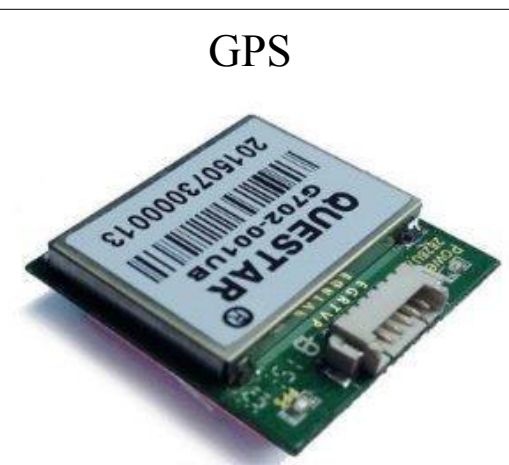

Figure 2: Diagram of GPS (G702-001UB). 


\section{SPEECH CIRCUIT}

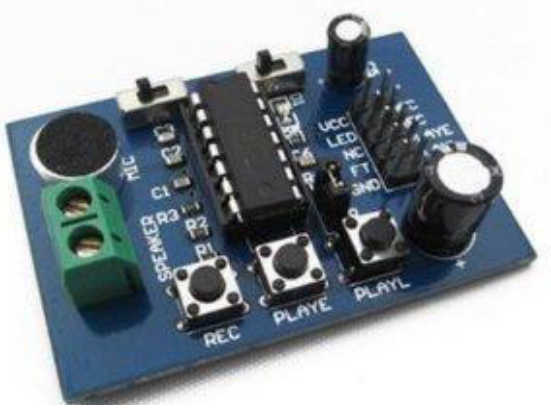

Figure 3: Diagram of speech circuit (ISD1820PY).

- We can drive a 8 ohm speaker.

- $\quad$ Voltage supply varies about $3 \mathrm{~V}$ to $5 \mathrm{~V}$.

- The audio of about 20 seconds can be recorded.

- Dimensions: $37 \times 55 \mathrm{~mm}$

\section{Simulation}

The program for our proposed model is coded in Embedded C language and is built using MPLAB software. The program is further tested in PROTEUS software. The GSM module is not available in proteus so we can use virtual terminal component to check the output of the GSM. The simulation output is given below.

Output: Using AT commands the GSM modem is able to send the message to the predefined numbers. Usually we prefer for information transfer to one or two numbers. But if necessary to send the message to many numbers, it is also possible. The numbers must be stored in the program of the microcontroller and must be dumped using the kit. The only problem is that it takes time to send message if the predefined numbers are more than three. Thus in the above output image we are able to see the transmission of message from the GSM modem to the predefined numbers using the virtual terminal [6-9].

\section{Advantages of the Proposed Device}

- Can be used for the safety of women.

- Can be used for the safety of children.

- $\quad$ Can be used for the safety of elderly aged people.

- $\quad$ Can be used for the safety of physically challenged people.

- Can be used as a legal evidence of crime with exact location information for prosecution.

\section{Applications of the Proposed Device}

- Compact in size.

- Wireless connectivity.

- $\quad$ Easy and fast to install.

- $\quad$ Easy Maintenance

- Low cost with high performance.

- Works round the clock.
- $\quad$ Fast response.

- Environmental friendly system.

\section{Conclusion}

Being safe and secure is the demand of the day. Our effort behind this project is to design and fabricate a gadget which is so compact in itself that provide advantage of personal security system. This design will deal with most of the critical issues faced by women and will help them to be secure. Existing systems provide the mechanism to track the vehicle but no other emergency mechanism is proposed. The proposed mechanism provides viewing the location of the victim in terms of latitude and longitude which can further be tracked using Google maps. This system helps to decrease the crime rate against women.

Women's security is a critical issue in current situation. These crimes can be brought to an end with the help of real time implementation of our proposed system.

\section{References}

1. Vijayalashmi B, Renuka S, Chennur P, Patil S (2015) Self defense system for women safety with location tracking and SMS alerting through GSM network. International Journal of Research in Engineering and Technology (IJRET) 4: 57-60.

2. Paradkar A, Sharma D (2015) All in one Intelligent Safety System for Women security. International Journal of Computer Applications 130: 33-40.

3. Bhilare P, Mohite A, Kamble D, Makode S, Kahane R (2015) Women Employee Security System using GPS And GSM Based Vehicle Tracking. International Journal for Research in Emerging Science and Technology 2: 65-71.

4. Premkumar $P$, CibiChakkaravarthi $R$, Keerthana $M$, Ravivarma $R$, Sharmila $T$ (2015) One Touch Alarm System For Women's Safety Using GSM. International Journal of Science, Technology \& Management 4: 1536-1539.

5. Bharadwaj N, Aggarwal N (2014) Design and Development of Suraksha-A women Safety Device. International Journal of Information \& Computation Technology 4: 787-792.

6. Baishya BK (2014) Mobile Phone Embedded With Medical and Security Applications. IOSR Journal of Computer Engineering 6: 30-33.

7. Mandapati S, Pamidi S, Ambati S (2015) A Mobile Based Women Safety Application (I Safe Apps). IOSR Journal of Computer Engineering 17: 29-34.

8. Chougula B, Naik A, Monu M, Patil P, Das P (2014) Smart Girls Security System. International Journal of Application or Innovation in Engineering and Management 3: 281-284.

9. Miriyala GP, Sunil PVVNDP, Yadlapalli RS, Pasam VRL, Kondapalli T, et al (2016) Smart Intelligent Security System for Women. International Journal of Electronics and Communication Engineering and Technology (IJECET) 7: 41-46. 